\title{
Coinfection of Ureaplasma urealyticum/Mycoplasma hominis in HPV Positive Women: Frequency, Risk Factors and Multidrug Resistance
}

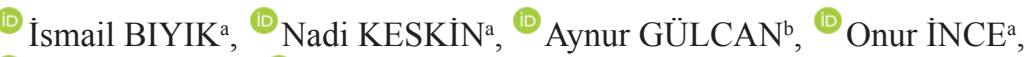 \\ Özlem ERTEN ${ }^{\text {a }}{ }^{\circledR 0}$ Halil İbrahim ȘंŞMAN ${ }^{a}$ \\ aDepartment of Obstetrics and Gynecology, Kütahya Health Sciences University Faculty of Medicine, Kütahya, TURKEY \\ ${ }^{b}$ Department of Medical Microbiology, Kütahya Health Sciences University Faculty of Medicine, Kütahya, TURKEY
}

\begin{abstract}
Objective: In the development of cervical cancer and its precursor, cervical intraepithelial neoplasia (CIN), the most significant cause is high-risk human papillomavirus (HPV) persistence. There are studies reporting high rates of co-prevalent Ureaplasma urealyticum in those who have an HPV infection. In this study, U. urealyticum positivity and antibiotic resistance rates were investigated in HPV positive women who were asymptomatic in terms of sexually transmitted disease. Material and Methods: In this retrospective cohort study, demographic data of the patients with HPV whose cervical swap were sent to the microbiology laboratory for Mycoplasma culture were obtained from hospital data management system. Mycoplasma culture is done by using a commercial kit (Mycoplasma IES (AutoBio Diagnostics, China) detecting Mycoplasma hominis and U. urealyticum and antibiotic susceptibility, simultaneously. The demographic data of the cases, HPV test, cervical smear, colposcopy findings and cervical biopsy results were compared according to the Mycoplasma/Ureaplasma culture and antibiogram results. Patients with multidrug-resistant $U$. urealyticum were evaluated according to risk factors. Results: HPV and U. urealyticum, HPV and M. hominis coinsidence were found as $43.1 \%$ and $1.5 \%$, respectively. No significant difference was found in terms of demographic data. HPV type, cervical smear, colposcopy and cervical biopsy findings were also not correlated with culture positivity. The multidrug-resistant (MDR) U. urealyticum ratio was 35.7\%. The most resistant and susceptible antibiotics are ciprofloxacin (96.4\%) and minocyclin (100\%), respectively. In patients with high-risk HPV positive, MDR positivity was significantly higher. Conclusion: In this study, it could not find any correlation of HPV type of cases, cervical smear results, colposcopy findings, cervical biopsy results with $U$. urealyticum culture results. Multi-drug resistant $U$. urealyticum (MDR-UU) positivity rates were detected statistically higher in the patients with highrisk-HPV. When HPV positivity is detected in reproductive women, existence of MDR-UU positivity should be considered.
\end{abstract}

Keywords: HPV, human papilloma virus; MDR; Ureaplasma urealyticum; sexually transmitted disease

Cervical cancer has a significant place worldwide in terms of cancer-related deaths in women. In the development of cervical cancer and its precursor, cervical intraepithelial neoplasia (CIN), the most important reason is high-risk human papillomavirus (HR-HPV) persistence. ${ }^{1}$ Factors such as smoking, high-parity, long-term use of oral contraceptives, other sexually transmitted infectious agents and coinfestation are thought to affect the progression to cervical cancer in HPV infected women. ${ }^{2,3}$ The geni- tal mycoplasmas are a class of pathogenic, the smallest free living bacteria in the ciliated epithelial cells of the urinary and genital tract of humans. ${ }^{4}$ The genital mycoplasmas colonized in the genital system consist of six types, including Ureaplasma urealyticum, Ureaplasma parvum, Mycoplasma hominis, Mycoplasma genitalium, Mycoplasma primatum and Mycoplasma spermatophilum. ${ }^{5}$ Some studies have shown that the rate of infection of $U$. urealyticum is high in HPV positive women. ${ }^{6}$ Similarly, there are

Correspondence: İsmail BIYIK

Department of Obstetrics and Gynecology, Kütahya Health Sciences University Faculty of Medicine, Kütahya, TURKEY

E-mail: dribiyik@hotmail.com

Peer review under responsibility of Journal of Clinical Obstetrics \& Gynecology. 
also different studies reporting co-prevalent $M$. hominis and $U$. urealyticum infection in those with HPV infection. In addition to HPV infection, the rate of $U$. urealyticum, co-infection was reported to be $19.5 \%$ in asymptomatic sexually active women. ${ }^{7}$

Although $U$. urealyticum co-infection with HPV is not uncommon, the biological role of $U$. urealyticum in HPV infection is not clearly understood. $U$. urealyticum is thought to be a cofactor in the development of HPV-mediated cervical dysplasia. ${ }^{8} U$. urealyticum may play a role in the onset of viral persistence and cellular anomalies., ${ }^{9,10}$ There are studies showing that Mycoplasma infection causes in vitro chromosomal changes and cell transformation, chromosomal loss, translocation. ${ }^{11}$ Similarly, in the presence of Mycoplasma infection, Robertsonian described chromosomal translocations. ${ }^{12}$ In this study, $U$. urealyticum positivity, antibiotic resistance rates and related risk factors were investigated in HPV positive women who are asymptomatic in terms of sexually transmitted disease.

\section{MATERIAL AND METHODS}

This retrospective cohort study was conducted between January 2020 and April 2020 at Kütahya Health Sciences University Evliya Celebi Training and Research Hospital after ethics approval of the study was obtained from the Non-interventional Research Ethics Committee of Kütahya University of Health Sciences (2020/06-10).

The patients between 25-62 years of age were sexually active and had no symptoms regarding sexually transmitted disease. Pregnant women and the women who had a hysterectomy, the ones receiving vaginal treatment within 3 days of cervical sampling, the ones who have been treated for cervical disease (such as LEEP) for the past 6 months, and those with vaginal or urethral discharge, itching in the external genital organs, dyspareunia, dysuria, vaginal bleeding in the form of spotting, haematuria and antibiotic users within fifteen days were not included in the study

The demographic data including age, body mass index (BMI), age of the first delivery, education level, marital status and laboratory data of the women 25-
62 years of age who were detected positivity therefore referred from Cancer Early Diagnosis Screening and Training Centre (CEDSTC) to Gynaecological Oncology Outpatient Clinic were analysed. The women applied to Gynaecological Oncology Outpatient Clinic with their HPV and Papanicolaou (Pap) smear test reports were taken cervical swap sample for Mycoplasma culture. Demographic data, HPV test, cervical smear, colposcopy findings and cervical biopsy results of the cases were compared according to U. urealyticum growth.

Pap smear results were classified according to the Bethesda system as "negative in terms of malignancy and intraepithelial lesion", "atypical squamous cells of undetermined significance (ASC-US)", "lowgrade squamous intraepithelial lesion (LSIL)" and "high grade squamous intraepithelial lesion (HSIL)". ${ }^{13}$ The colposcopic examination results were grouped as "no lesion", "acetowhite epitel", "punctuation", "mosaism". In the cervical biopsy, intraepithelial lesions were classified as CIN I, II, III according to the degree of dysplasia. ${ }^{14}$

The colposcopy indications of our clinic were performed according to The American Society for Colposcopy and Cervical Pathology Colposcopy Standarts: abnormal or inconclusive Pap smear test, abnormality found during pelvic examination, abnormal genital tract bleeding, or unexplained cervicovaginal discharge and past cytologic and/or pathologic anogenital tract abnormalities. ${ }^{15}$

\section{HUMAN PAPILLOMAVIRUS SCREENING}

The patients applied to the institution with HPV screening. In (CEDSTC) HPV sampling of the patients was done with the Digene HPV HC2 DNA test kit (Qiagen, Hilden, Germany) on the DML 3000 luminometer device. It was learned that HPV typing of positive cases was determined by applying PCR using EZ1 virus mini kit (Qiagen, Hilden, Germany). 16, 18, 26, 31, 33, 35, 39, 45, 51, 52, 53, $56,58,59,66,68,73$ and 83 were accepted as HRHPV types. 6, 11, 40, 42, 43, 44, 54, 61, 70, 72 and 81 were accepted as low-risk-HPV (LR-HPV) types. 


\section{MYCOPLASMA HOMINIS AND UREAPLASMA UREALYTICUM SCREENING}

Detection of $M$. hominis and $U$. urealyticum in the genitourinary system samples, identification and antibiotic susceptibility tests were performed using the Mycoplasma IES (AutoBio Diagnostics, China) kit in the microbiology laboratory. Based on the bacterial production and biochemical reactions, the blend medium of the kit was prepared in accordance with the package insert, by mixing frozen-dry powder and diluent. Thanks to the enzymes that break down urea and $M$. hominis arginine of $U$. urealyticum, the result was evaluated on the basis of increasing the $\mathrm{pH}$ in the liquid medium of NH3 and the colour change of the indicator. Also, the sensitivity of Clinical \& Laboratory Standards Institute (CLSI) to 11 antibiotics from three groups recommended for antibiogram was tested. Since it was naturally resistant to $U$. urealyticum clindamycin, it was not evaluated in statistical analysis. In the data evaluated retrospectively, the susceptibility levels were analysed by accepting low susceptible strains as resistant.

\section{STATISTICAL ANALYSIS}

SPSS $^{\circledR}$ software (SPSS 15.0, SPSS, Chicago, IL, USA) was used for statistical analysis. The suitability of the data for normal distribution was determined by the Shapiro-Wilk test. Variables were expressed as mean \pm standard deviation or median (Q25-Q75). Continuous variables were compared with Student ttest or Mann-Whitney U test. Categorical variables were compared with chi-square test or Fisher's exact test. In the comparison of ordered categorical variables, Mantel-Haenszel chi-square test was used. $\mathrm{p}<0.05$ was considered statistically significant.

\section{RESULTS}

The mean age of the cases was calculated as $43.8 \pm 8.7$ years. When the demographic data of the cases were compared according to the $U$. urealyticum culture result, no significant difference was found in terms of age, height, weight, first coitus age, total number of partners, age of first birth, education level, marital status, use of contraception method, vaginal douche, infertility, chronic disease, operation, medication use (e.g antihypertensive), smoking, menopause history
( $p>0.05)$. Demographic data are given in Table 1. In this study, in HPV positive women who are asymptomatic in terms of sexually transmitted diseases, $U$. urealyticum positivity rate was found to be $43.1 \%$. In addition to $U$. urealyticum in $1(1.5 \%)$ case, $M$. hominis was also found positive.

When the HPV type of the cases, cervical smear result, colposcopy findings and cervical biopsy results were compared according to the $U$. urealyticum culture result, no significant difference was found $(p>0.05)$. HPV type, cervical smear result, colposcopy findings and cervical biopsy results are given in Table 2.

In $28(43.1 \%)$ of the cervical swab samples taken from the patients, $\geq 10^{4} \mathrm{CFU} / \mathrm{mL} U$. urealyticum reproduced. When antibiotic susceptibility test results are evaluated, the most sensitive antibiotics were minocycline (100\%), erythromycin and josamycin $(82.1 \%)$, levofloxacin $(78.6 \%)$ and roxithromycin $(71.4 \%)$, respectively. The antibiotics that this bacterium is most resistant to was determined as ciprofloxacin (96.4\%) and ofloxacin (53.6\%) (Table $3)$. The multidrug-resistant (MDR) UU ratio of at least one antibiotic-resistant from each of the tested tetracycline, macrolide and quinolone group antibiotics was $35.7 \%(n=10)$.

No statistical difference was found between MDR-UU positivity and demographic and other features ( $p>0.05)$. MDR-UU positivity rates were to be higher in the patients with high risk-HPV $(p=0.049)$ (Table 4)

\section{DISCUSSION}

In this study, U. urealyticum positivity rate was found to be $43.1 \%$ in HPV positive women who were asymptomatic in terms of sexually transmitted disease. When the HPV type, cervical smear result, colposcopy findings and cervical biopsy results were compared in terms of the $U$. urealyticum culture result, no significant difference was found.

The most important reason for the development of cervical cancer and its precursor, CIN, is a HRHPV persistence. ${ }^{1}$ The causality relationship between cervical cancer and HPV is clear. However, it is thought that facilitating factors are needed for HPV 
TABLE 1: Comparison of the demographic data of the cases according to the Ureaplasma urealyticum culture result.

\begin{tabular}{|c|c|c|c|c|c|c|}
\hline & & \multicolumn{4}{|c|}{ U. urealyticum } & \multirow[b]{3}{*}{$\mathrm{p}$} \\
\hline & & \multicolumn{2}{|c|}{ Negative } & \multicolumn{2}{|c|}{ Positive } & \\
\hline & & Mean & Standard deviation & Mean & Standard deviation & \\
\hline Age (year) & & 45.3 & 9.9 & 41.8 & 6.3 & $0.086^{a}$ \\
\hline Height (cm) & & 158.2 & 5.3 & 158.1 & 5.8 & $0.968^{a}$ \\
\hline Weight (kilogram) & & 67.5 & 12.6 & 69.3 & 16.9 & $0.947^{b}$ \\
\hline Age at first coitus (year) & & 19.1 & 3.1 & 19.4 & 3.7 & $0.584^{b}$ \\
\hline Total number of partners & & 1.2 & 0.6 & 1.7 & 1.6 & $0.111^{b}$ \\
\hline \multirow{2}{*}{\multicolumn{2}{|c|}{ Age at first delivery (year) }} & 21.4 & 4.0 & 22.2 & 4.5 & $0.446^{b}$ \\
\hline & & $\mathrm{n}$ & $\%$ & $\mathrm{n}$ & $\%$ & \\
\hline \multirow[t]{6}{*}{ Education level } & Illiterate & 4 & 10.8 & 1 & 3.6 & $0.854^{c}$ \\
\hline & Primary school & 19 & 51.4 & 17 & 60.7 & \\
\hline & Middle school & 4 & 10.8 & 3 & 10.7 & \\
\hline & High school & 8 & 21.6 & 5 & 17.9 & \\
\hline & Two-years degree & 1 & 2.7 & 0 & 0.0 & \\
\hline & Bachelor' degree & 1 & 2.7 & 2 & 7.1 & \\
\hline \multirow[t]{3}{*}{ Marital status } & Married & 32 & 86.5 & 21 & 75.0 & $0.338^{c}$ \\
\hline & Single & 0 & 0.0 & 1 & 3.6 & \\
\hline & Divided & 5 & 13.5 & 6 & 21.4 & \\
\hline \multirow[t]{6}{*}{ Using contraception method } & No & 20 & 54.1 & 13 & 46.4 & $0.883^{c}$ \\
\hline & Condom & 7 & 18.9 & 7 & 25.0 & \\
\hline & OKP & 2 & 5.4 & 2 & 7.1 & \\
\hline & IUD & 3 & 8.1 & 4 & 14.3 & \\
\hline & Coitus interruptus & 2 & 5.4 & 1 & 3.6 & \\
\hline & BTL & 3 & 8.1 & 1 & 3.6 & \\
\hline \multirow[t]{2}{*}{ Vaginal douche } & Yes & 29 & 78.4 & 20 & 71.4 & $0.520^{\circ}$ \\
\hline & No & 8 & 21.6 & 8 & 28.6 & \\
\hline \multirow[t]{2}{*}{ Infertility } & No & 33 & 89.2 & 24 & 85.7 & $0.717^{d}$ \\
\hline & Yes & 4 & 10.8 & 4 & 14.3 & \\
\hline \multirow[t]{2}{*}{ Chronic disease } & No & 24 & 64.9 & 13 & 46.4 & $0.137^{\circ}$ \\
\hline & Yes & 13 & 35.1 & 15 & 53.6 & \\
\hline \multirow[t]{2}{*}{ Operation history } & No & 16 & 43.2 & 16 & 57.1 & $0.267^{c}$ \\
\hline & Yes & 21 & 56.8 & 12 & 42.9 & \\
\hline \multirow[t]{2}{*}{ Medication use } & No & 25 & 67.6 & 16 & 57.1 & $0.388^{c}$ \\
\hline & Yes & 12 & 32.4 & 12 & 42.9 & \\
\hline \multirow[t]{2}{*}{ Smoking } & No & 26 & 70.3 & 20 & 71.4 & $0.919^{c}$ \\
\hline & Yes & 11 & 29.7 & 8 & 28.6 & \\
\hline \multirow[t]{2}{*}{ Menopause status } & Premenopause & 26 & 70.3 & 23 & 82.1 & $0.271^{\mathrm{c}}$ \\
\hline & Postmenopause & 11 & 29.7 & 5 & 17.9 & \\
\hline
\end{tabular}

OCP: Oral contraceptive pills, IUD: Intrauterine device, BTL: Bilateral tubal ligation.

aStudent t-test, ${ }^{b}$ Mann-Whitney $\mathrm{U}$ test, ${ }^{\mathrm{c}} \mathrm{Chi}$-square test, ${ }^{\mathrm{d}}$ Fisher's exact test.

infection to cause cervical cancer. These facilitating factors include many sexual partners and environmental factors such as sexually transmitted diseases. ${ }^{8}$

Most studies argue that Mycoplasma/Ureaplasma infection positivity increases the likelihood of acquiring HPV infection. U. urealyticum and M. genitalium are the most common species having coincidence with
HPV infection. ${ }^{7,16,17}$ In the study conducted by Kim et al., U. urealyticum $\left(>10^{4} \mathrm{CFU} / \mathrm{mL}\right)$, which forms a high-density colony, was associated with HPV infection. ${ }^{7}$ Verteramo et al., and Ekiel et al. stated that $U$. urealyticum $\left(>10^{4} \mathrm{CFU} / \mathrm{mL}\right)$ may be a risk factor for HPV infection in asymptomatic women. ${ }^{6,7,18}$ Lukic et al,. reported that the presence of $U$. urealyticum $\left(>10^{4}\right.$ 


\begin{tabular}{|c|c|c|c|c|c|c|}
\hline & & \multicolumn{4}{|c|}{ U. urealyticum } & \multirow[b]{3}{*}{$p$} \\
\hline & & \multicolumn{2}{|c|}{ Negative } & \multicolumn{2}{|c|}{ Positive } & \\
\hline & & $\mathrm{n}$ & $\%$ & $\mathrm{n}$ & $\%$ & \\
\hline \multicolumn{7}{|l|}{ HPV type } \\
\hline & High-risk & 32 & 88.9 & 22 & 78.6 & $0.259^{\mathrm{a}}$ \\
\hline & Low-risk & 4 & 11.1 & 6 & 21.4 & \\
\hline \multicolumn{7}{|l|}{ Cervical smear result } \\
\hline & Intraepithelial lesion negative & 23 & 63.9 & 15 & 53.6 & $0.544^{b}$ \\
\hline & ASCUS* & 7 & 19.4 & 9 & 32.1 & \\
\hline & $\mathrm{LSIL}^{* *}$ & 6 & 16.7 & 4 & 14.3 & \\
\hline & $H S I L^{* * *}$ & 0 & 0.0 & 0 & 0.0 & \\
\hline \multirow[t]{4}{*}{ Colposcopy findings } & No lesion & 11 & 29.7 & 4 & 14.3 & $0.343^{\mathrm{a}}$ \\
\hline & Acetowhite epithelium & 13 & 35.1 & 12 & 42.9 & \\
\hline & Punctuation & 13 & 35.1 & 12 & 42.9 & \\
\hline & Mosaicism & 0 & 0.0 & 0 & 0.0 & \\
\hline \multirow[t]{3}{*}{ Cervical biopsy result } & Chronic cervicitus & 25 & 67.6 & 15 & 53.6 & $0.323^{b}$ \\
\hline & $\mathrm{CIN}^{\star \star * *}$ & 7 & 18.9 & 9 & 32.1 & \\
\hline & CIN II-III & 5 & 13.5 & 4 & 14.3 & \\
\hline
\end{tabular}

HPV: Human papilloma virus, ASCUS: Atypical squamous cells of undetermined significance, LSIL: Low grade squamous intraepithelial lesion, HSIL: High grade squamous intraepithelial lesion, CIN: Cervical intraepithelial neoplasia.

${ }^{\mathrm{a} C h i-s q u a r e}$ test, ${ }^{\mathrm{b}}$ Mantel-Haenszel chi-square test.

$\mathrm{CFU} / \mathrm{mL}$ ) in women might be a cofactor for HPV and adversely affect the results of cervical cytology. ${ }^{9}$ In the study of Biernat-Sudolska et al., they showed that the rate of detection of $U$. urealyticum in cases with cervical cancer is higher than women with normal cytology. ${ }^{19}$ Pisani et al., found a positive relationship between $U$. urealyticum and HPV infection and claimed that Ureaplasma urealyticum and HPV might have a synergistic effect in the formation of CIN and cervical cancer. ${ }^{20}$ However, in this study, U. urealyticum did not affect cervical cytology results.

Lopez-Arias et al., found a correlation between $M$. hominis/U. urealyticum and high risk-HPV infection, but could not find a relationship between the severity of $U$. urealyticum coinfection and cervical lesions. ${ }^{21}$ On the contrary, in the cervical microbial environment study investigating the factors affecting HPV clearance rates, the presence of $U$. urealyticum was shown to increase HPV clearance. ${ }^{22}$ In this study, no relation was found between $U$. urealyticum and high risk-HPV coinfection and severity of cervical lesions.

In the literature, U. urealyticum rates differ in HPV positive women. In the study of Kim et al., they reported the prevalence of $U$. urealyticum as $36 \%$,

\begin{tabular}{|lcccc|}
\hline \multicolumn{4}{|c|}{ TABLE 3: Ureaplasma urealyticum antibiotic susceptibility rates. } \\
\hline & \multicolumn{2}{c}{ Susceptible } & \multicolumn{2}{c|}{ Resistant } \\
& $\mathrm{n}$ & $\%$ & $\mathrm{n}$ & $\%$ \\
\hline Minocycline & 28 & 100 & & \\
\hline Tetracycline & 15 & 53.6 & 13 & 46.4 \\
\hline Erythromycin & 23 & 82.1 & 5 & 17.9 \\
\hline Clarithromycin & 17 & 60.7 & 11 & 39.3 \\
\hline Roxithromycin & 20 & 71.4 & 8 & 28.6 \\
\hline Josamycin & 23 & 82.1 & 5 & 17.9 \\
\hline Ofloxacin & 13 & 46.4 & 15 & 53.6 \\
\hline Ciprofloxacin & 1 & 3.6 & 27 & 96.4 \\
\hline Levofloxacin & 22 & 78.6 & 6 & 21.4 \\
\hline
\end{tabular}

and the coincidence of $U$. urealyticum with HPV as $19.5 \% .^{7}$ Zhang et al. reported the prevalence of Ureaplasma urealyticum as $35.5 \%$, and HPV and Ureaplasma urealyticum coincidence as $8.6 \%$ in symptomatic women. ${ }^{10} \mathrm{Lv}$ et al. found the prevalence of $U$. urealyticum as $15.4 \%$ in women with HR-HPV positive, and $8.6 \%$ in U. urealyticum in women with HR-HPV negative. ${ }^{23}$ Parthenis et al.also found that the rate of positive HR-HPV types was $25.4 \%$ and the positive rate of LR-HPV types was $7.9 \%$ in women who had positive Ureaplasma test. ${ }^{17}$ Lopez-Arias et al., reported $U$. urealyticum coincidence with HPV as 


\begin{tabular}{|c|c|c|c|c|c|c|}
\hline & & \multicolumn{2}{|c|}{ No multidrug-resistant UU ( $n=18)$} & \multicolumn{2}{|c|}{ Multidrug-resistant UU $(n=10)$} & \multirow[b]{2}{*}{$\mathrm{p}$} \\
\hline & & Mean & Standard deviation & Mean & Standard deviation & \\
\hline Age (year) & & 42.5 & 5.72 & 40.4 & 7.41 & $0.449^{a}$ \\
\hline \multirow[t]{2}{*}{$\mathrm{BMI}\left(\mathrm{kg} / \mathrm{m}^{2}\right)$} & & 26.54 & 3.98 & 29.57 & 8.6 & $0.318^{\mathrm{a}}$ \\
\hline & & $\mathrm{n}$ & $\%$ & $\mathrm{n}$ & $\%$ & \\
\hline \multirow[t]{2}{*}{ Education level } & Middle School or below & 14 & $66.7 \%$ & 7 & $33.3 \%$ & $0.674^{b}$ \\
\hline & High School and above & 4 & $57.1 \%$ & 3 & $42.9 \%$ & \\
\hline \multirow[t]{2}{*}{ Marital status } & Married & 14 & $66.7 \%$ & 7 & $33.3 \%$ & $0.674^{b}$ \\
\hline & Single & 4 & $57.1 \%$ & 3 & $42.9 \%$ & \\
\hline \multirow[t]{2}{*}{ Vaginal douche } & Yes & 13 & $65 \%$ & 7 & $35 \%$ & $1.000^{b}$ \\
\hline & No & 5 & $62.5 \%$ & 3 & $37.5 \%$ & \\
\hline \multirow[t]{2}{*}{ Infertility history } & No & 15 & $62.5 \%$ & 9 & $37.5 \%$ & $1.000^{\mathrm{b}}$ \\
\hline & Yes & 3 & $75 \%$ & 1 & $25 \%$ & \\
\hline \multirow[t]{2}{*}{ Operation history } & No & 11 & $58.3 \%$ & 5 & $31.3 \%$ & $0.698^{b}$ \\
\hline & Yes & 7 & $56.8 \%$ & 5 & $41.7 \%$ & \\
\hline \multirow[t]{2}{*}{ Medicine use } & No & 11 & $68.8 \%$ & 5 & $31.3 \%$ & $0.698^{b}$ \\
\hline & Yes & 7 & $58.3 \%$ & 5 & $41.7 \%$ & \\
\hline \multirow[t]{2}{*}{ Smoking } & No & 14 & $60.9 \%$ & 9 & $39.1 \%$ & $0.400^{b}$ \\
\hline & Yes & 4 & $80 \%$ & 1 & $20.0 \%$ & \\
\hline \multirow[t]{2}{*}{ Menopausal status } & Premenopausal & 14 & $60.9 \%$ & 9 & $39.1 \%$ & $0.271^{b}$ \\
\hline & Postmenopausal & 4 & $80 \%$ & 1 & $20 \%$ & \\
\hline \multirow[t]{2}{*}{ HPV } & High-risk & 12 & $54.5 \%$ & 10 & $45.5 \%$ & $0.049^{b}$ \\
\hline & Low-risk & 6 & $100 \%$ & 0 & $0 \%$ & \\
\hline
\end{tabular}

BMI: Body mass index, HPV: Human papillomavirus.

aMann-Whitney $U$ test, ${ }^{b}$ Chi-square test.

$16.7 \% .{ }^{21}$ In the study of Biernat-Sudolska et al., Ureaplasma and/or Mycoplasma coinfection rate with HPV was reported as $24 \% .{ }^{19}$ In the same study, they reported the $M$. hominis prevalence as $1 \%$. In this study, in HPV positive women, U. urealyticum positivity rate was found to be $43.1 \%, M$. hominis prevalence was $1.5 \%$ in line with the literature.

Since Mycoplasmas' do not have a rigid cell wall, they are naturally resistant to beta-lactam antibiotics and vancomycin. U. urealyticum is also naturally resistant to lincosamides, thereby macrolides, quinolones and tetracyclines, which are protein synthesis inhibitors, are often used in treatment. Also, it showed resistance to these drugs at various rates. Besli et al., reported that antibiotics with the highest susceptibility rates for $U$. urealyticum detected in the samples of the genitourinary system were minocycline (98.5\%), doxycycline (98.1\%) and josamycin $(98.1 \%) .{ }^{24}$ Bayraktar et al., found $100 \%$ sensitivity to doxycycline, tetracycline and pristinamine, $92.6 \%$ to josamine and $88.9 \%$ to clarithromycin, and found the highest resistance against ciprofloxacin $(92.6 \%)$ and ofloxacin $(85.2 \%) .{ }^{25}$ Khan et al., found minocycline and doxycycline as the most effective antibiotics, and the activity of erythromycin to be quite high, and the highest resistance against tetracycline. ${ }^{26}$ Michael et al., found that levofloxacin and moxifloxacin were more effective than ciprofloxacin, and all strains were susceptible to macrolides (erythromycin and azithromycin). ${ }^{27}$ In line with the literature, in this study, it was found that minocycline had a significantly higher susceptibility compared to tetracycline, and levofloxacin was significantly more susceptible than other quinolones (ofloxacin and ciprofloxacin) (78.6\% vs. $46 \%$ and $3.6 \%$ ), and except for clarithromycin, which is one of the macrolides, was similarly susceptible ( $78.6 \%$ vs. $82.1 \%)$. In this study, due to the lack of HPV negative control group, it was not found whether $U$. urealyticum coinfection increased the risk of developing a HPV infection. Also, the case number in this study was relatively low. These factors can be considered as limitations of the study. 


\section{CONCLUSION}

In this study, no correlation of HPV type of cases, cervical smear results, colposcopy findings, cervical biopsy results with $U$. urealyticum culture results. MDR-UU positivity rates were detected statistically were found higher in the patients with HR-HPV. When HPV positivity is detected in reproductive women, existence of MDR-UU positivity should be considered.

\section{Source of Finance}

During this study, no financial or spiritual support was received neither from any pharmaceutical company that has a direct connection with the research subject, nor from a company that provides or produces medical instruments and materials which may negatively affect the evaluation process of this study.

\section{Conflict of Interest}

No conflicts of interest between the authors and / or family members of the scientific and medical committee members or members of the potential conflicts of interest, counseling, expertise, working conditions, share holding and similar situations in any firm.

\section{Authorship Contributions}

Idea/Concept: Ismail Blylk, Nadi Keskin, Özlem Erten; Design: İsmail Bıyık, Aynur Gülcan, Nadi Keskin, Halil İbrahim Şişman; Control/Supervision: İsmail Bıyık, Onur Ince, Aynur Gülcan; Data Collection and/or Processing: Ísmail Blyık, Nadi Keskin, Halil İbrahim Şişman; Analysis and/or Interpretation: İsmail Blyık, Onur Ince, Aynur Gülcan; Literature Review: İsmail Bıylk, Özlem Erten, Aynur Gülcan; Writing the Article: Ismail Bıyık, Aynur Gülcan; Critical Review: Nadi Keskin, Özlem Erten; References and Fundings: Halil İbrahim Şişman.

\section{REFERENCES}

1. Bosch FX, Lorincz A, Mu-oz N, Meijer CJLM, Shah KV. The causal relation between human papillomavirus and cervical cancer. J Clin Pathol. 2002;55(4):244-65. [Crossref] [PubMed] [PMC]

2. Castellsagué $\mathrm{X}, \mathrm{Mu}-\mathrm{oz} \mathrm{N}$. Chapter 3: cofactors in human papillomavirus carcinogenesis-role of parity, oral contraceptives, and tobacco smoking. J Natl Cancer Inst Monogr. 2003;(31):20-8. [Crossref] [PubMed]

3. Arnheim Dahlström L, Andersson K, Luostarinen T, Thoresen S, Ögmundsdottír H, Tryggvadottír L, et al. Prospective seroepidemiologic study of human papillomavirus and other risk factors in cervical cancer. Cancer Epidemiol Biomarkers Prev. 2001;20(12): 2541-50. [Crossref] [PubMed]

4. Tully JG, Taylor-Robinson D, Cole RM, Rose $\mathrm{DL}$. A newly discovered mycoplasma in the human urogenital tract. Lancet. 1981;13;1(8233):1288-91. [Crossref] [PubMed]

5. Ljubin-Sternak S, Meštrović T. Chlamydia trachomatis and Genital Mycoplasmas: Pathogens with an Impact on Human Reproductive Health. J Pathog. 2014;2014:183167. [Crossref] [PubMed] [PMC]

6. Verteramo R, Pierangeli A, Mancini E, Calzolari E, Bucci M, Osborn J, et al. Human papillomaviruses and genital coinfections in gynaecological outpatients. BMC Infect Dis. 2009;12;9:16. [Crossref] [PubMed] [PMC]

7. Kim SI, Yoon JH, Park DC, Lee DS, Lee SJ, Choe HS, et al. Co-infection of ureaplasma urealyticum and human papilloma virus in asymptomatic sexually active individuals. Int J Med Sci. 2018;12;15(9):915-20. [Crossref] [PubMed] [PMC]

8. Lukic A, Canzio C, Patella A, Giovagnoli M, Cipriani P, Frega A, et al. Determination of cervicovaginal microorganisms in women with abnormal cervical cytology: the role of Ureaplasma urealyticum. Anticancer Res. 2006;26(6C):4843-9. [PubMed]

9. Liu J, Liu W, Liu Y, Zhou X, Zhang Z, Sun Z, et al. Prevalence of microorganisms co- infections in human papillomaviruses infected women in Northern China. Arch Gynecol Obstet. 2016;293(3):595-602. [Crossref] [PubMed]

10. Zhang D, Li T, Chen L, Zhang X, Zhao G, Liu $Z$, et al. Epidemiological investigation of the relationship between common lower genital tract infections and high-risk human papillomavirus infections among women in Beijing, China. PLoS One. 2017;22;12(5):e0178033. [Crossref] [PubMed] [PMC]

11. Macpherson I, Russell W. Transformations in hamster cells mediated by mycoplasmas. $\mathrm{Na}-$ ture. 1966;25;210(5043):1343-5. [Crossref] [PubMed]

12. Tsai S, Wear DJ, Shih JW, Lo SC. Mycoplasmas and oncogenesis: persistent infection and multistage malignant transformation. Proc Nat Acad Sci USA. 1995;24;92(22):10197-201. [Crossref] [PubMed] [PMC]

13. Nayar R, Wilbur DC. The Pap test and Bethesda 2014. Cancer Cytopathol. 2015;123(5):271-81. [Crossref] [PubMed]
14. Smith JHF. Bethesda 2001. Cytopathology. 2002;13(1):4-10. [Crossref] [PubMed]

15. Khan MJ, Werner CL, Darragh TM,Guido RS, Mathews C, Moscicki AB, et al. ASCCP colposcopy standards: role ofcolposcopy, benefits, potential harms, and terminology for colposcopic practice. J Low Genit Tract Dis. 2017;21(4):223-9. [PubMed]

16. Ye H, Song T, Zeng X, Li L, Hou M, Xi M, et al Association between genital mycoplasmas infection and human papillomavirus infection, abnormal cervical cytopathology, and cervical cancer: a systematic review and meta-analysis. Arch Gynecol Obstet. 2018;297(6):137787. [Crossref] [PubMed]

17. Parthenis $C$, Panagopoulos $P$, Margari N, Kottaridi C, Spathis A, Pouliakis A, et al. The association between sexually transmitted infections, human papillomavirus, and cervical cytology abnormalities among women in Greece. Int J Infect Dis. 2018;73:72-7. [Crossref] [PubMed]

18. Ekiel AM, Friedek DA, Romanik MK, Józ?wiak J, Martirosian G. Occurrence of Ureaplasma parvum and Ureaplasma urealyticum in women with cervical dysplasia in Katowice Poland. J Korean Med Sci. 2009:24(6):117781. [Crossref] [PubMed] [PMC]

19. Biernat-Sudolska M, Szostek S, Rojek-Zakrzewska D, Klimek M, Kosz-Vnenchak M. Concomitant infections with human papillomavirus and various mycoplasma and ureaplasma species in women with abnormal cervical cytology. Adv Med Sci. 2011;56(2):299-303. [Crossref] [PubMed] 
20. Pisani S, Gallinelli C, Seganti L, Lukic A, Nobili $F$, Vetrano $G$, et al. Detection of viral and bacterial infections in women with normal and abnormal colposcopy. Eur J Gynaecol Oncol. 1999;20(1):69-73. [PubMed]

21. Lopez-Arias M, Vazquez-Jimenez S, MartinezAbundis E, Gomez-Crisostomo NP, ChavezBlanco A, Contreras-Paredes A, et al. Genital association of human papillomavirus with Mycoplasma and Ureaplasma spp. in Mexican women with precancerous lesions. Int J STD AIDS. 2019;30(10):969-77. [Crossref] [PubMed]

22. Arokiyaraj S, Seo SS, Kwon M, Lee JK, Kim MK. Association of cervical microbial community with persistence, clearance and negativity of Human Papillomavirus in Korean women: a longitudinal study. Sci Rep. 2018;19;8(1): 15479. [Crossref] [PubMed] [PMC]

23. Lv $P$, Zhao $F, X u X, X u$ J, Wang $Q$, Zhao Z, et al. Correlation between common lower genital tract microbes and high-risk human papillomavirus infection. Can J Infect Dis Med Microbiol. 2019;22;2019:9678104. [Crossref] [PubMed] [PMC]

24. Bepli Y, Karatuna O, Akyar I. [Evaluation of in vitro antimicrobial susceptibility in ureaplasma urealyticum and mycoplasma hominis strains isolated from genitourinary tract samples]. ANKEM Derg. 2017;31(3):97-105.

25. Bayraktar MR, Ozerol IH, Gucluer N, Celik O.
Prevalence and antibiotic susceptibility of Mycoplasma hominis and Ureaplasma urealyticum in pregnant women. Int $\mathrm{J}$ Infect Dis. 2010;14(2):e90-5. [Crossref] [PubMed]

26. Khan J, Farzand R, Ghumro PB. Antibiotic sensitivity of human genital mycoplasmas. African Journal of Microbiology Research. 2010;4(9):704-7.

27. Beeton ML, Chalker VJ, Jones LC, Maxwell NC, Spiller OB. Antibiotic resistance among clinical Ureaplasma isolates recovered from Neonates in England and Wales between 2007 and 2013. Antimicrobial Agents and Chemotherapy. 2016:60(1):52-6. [Crossref] [PubMed] [PMC] 